\title{
Absence of amosite asbestos in airway mucosa of non-smoking long term workers with occupational exposure to asbestos
}

\author{
Andrew Churg, B Stevens
}

\begin{abstract}
There is considerable experimental evidence that asbestos fibres are taken up by epithelial cells, and that uptake of fibres is associated with various deleterious, particularly mutagenic, effects. It is not known, however, if asbestos fibres are taken up by human bronchial epithelial cells in vivo. To investigate this question, the amosite asbestos content of the mucosa of seven different airways and four parenchymal sites supplied by these airways in six necropsy lungs from heavily exposed never-smoking long term shipyard and insulation workers without asbestosis was examined. Amosite asbestos was readily found in moderately high concentration in all parenchymal samples, but 33 of $\mathbf{4 0}$ airway samples that could be evaluated showed no amosite fibres. The seven positive airways had fibre concentrations that were always much lower than the parenchymal concentrations, and these very few fibres may have been contaminants from the parenchyma. These data suggest that, at least in non-smokers, amosite asbestos either does not penetrate into or does not accumulate in human airway mucosa. These findings also call into question the idea that asbestos acts as a direct airway carcinogen in humans.
\end{abstract}

(British Journal of Industrial Medicine 1993;50:355-359)

In general asbestos seems to produce disease through various locally mediated rather than systemic effects. The most consistent findings in experimental animal and tissue culture systems have been that epithelial cells take up asbestos fibres, and that fibre uptake is

Department of Pathology and University Hospital, University of British Columbia, Vancouver, BC, Canada V6T $2 B 5$

A Churg, B Stevens associated with deleterious effects relating to both fibrogenesis and carcinogenesis ${ }^{1-3}$ (see discussion).

Although fibre uptake by bronchial epithelial cells is well established in experimental models, it is not known to what degree the same process occurs in humans, or even whether it occurs at all. We have recently devised a technique for analysing the particle content of respiratory bronchial mucosa from human necropsies, ${ }^{4}$ and in this paper we apply the technique to look at airway and parenchymal asbestos retention in workers with substantial occupational exposure to amosite asbestos.

\section{Materials and methods \\ CASE SELECTION}

Cases for this study were selected from persons with occupational exposure to amosite asbestos whose lungs at necropsies were referred to this laboratory for evaluation of asbestos content. These persons had been exposed to asbestos in the Pacific north west in shipyards or as career asbestos insulators and similar trades in which high level asbestos exposure was known to have occurred.

As this study was intended to provide baseline data on fibre burden in the airway mucosa free of interference by variables that might affect fibre retention, we restricted the study to lungs that were essentially pathologically normal. Small amounts of pneumonia were considered acceptable. We also decided to restrict the study to non-smokers because smoking may change fibre uptake. ${ }^{5}$ Because we did not know which airways were likely to accumulate asbestos fibres and because we needed to ensure a broad sample of airways, analyses were restricted to lungs in which several different airways matching the scheme shown could be found. Lastly, to ensure that the population sampled had a reasonably heavy exposure, only cases with greater than 10 years of exposure were used.

\section{TISSUE SAMPLING}

Application of the conditions just described resulted in selection of six lungs, all of which turned out to be from patients with mesothelioma. Only the lung 
Table 1 Demographic data

\begin{tabular}{llllllll}
\hline Case & 1 & 2 & 3 & 4 & 5 & 6 & Mean (SD) \\
\hline Age (y) & 50 & 65 & 68 & 76 & 70 & 79 & $68(10)$ \\
Sex & $M$ & $M$ & $M$ & $M$ & $M$ & $M$ & \\
Exposure (y) & 15 & 35 & 25 & 36 & 22 & 30 & $28(8)$ \\
Latency (y) & 32 & 61 & 48 & 49 & 48 & 49 & $48(9)$ \\
Years since last exposure & 17 & 26 & 23 & 13 & 26 & 19 & $21(5)$ \\
\hline
\end{tabular}

without a tumour was used. All lungs were fixed in formalin by the original pathologist before referral to our laboratory. The lungs were sliced in a sagittal plane, and the listed airways were examined; the sites were designed to sample airways of varying size, distance from the carina, and orientation with respect to gravity. The sample sites were:

Mainstream bronchus (MAIN)

Upper lobe bronchus (ULB)

Apical segmental bronchus upper lobe (APB)

Anterior segental bronchus upper lobe (ASB)

Lower lobe bronchus (LLB)

Superior segmental bronchus lower lobe (SSB) (PBB)

Posterior basal segmental bronchus lower lobe

The airway mucosa was sampled by isolating a roughly $1 \mathrm{~cm}$ long segment of airway ${ }^{4}$; the airway was carefully rinsed with saline to remove adherent mucus, and the mucosa (defined here as all tissue from the epithelium to the top of the cartilage) separated from the underlying cartilage by sharp dissection.

To provide a comparison of parenchymal content of asbestos, samples were also taken from the sites supplied by the segmental airways just listed:

Apical segmental parenchyma upper lobe (APT) (AST)

Anterior segmental parenchyma upper lobe (SST)

Superior segmental parenchyma lower lobe

Posterior basal segmental parenchyma lower lobe (PBT)

The parenchymal samples consisted of wedge shaped pieces of tissue based on the pleura and with the apex of the wedge extending to the site of the sample of segmental airway.

\section{PREPARATION OF TISSUE FOR ASBESTOS AND PARTICLE} IDENTIFICATION

Airway or parenchymal samples were dissolved in bleach and the mineral particles collected on millipore filters and then transferred to coated electron microscope grids as previously described. ${ }^{6}$ Preparations were examined in a Phillips 400T electron microscope equipped with a Kevex energy dispersive $x$ ray spectrometer. For the parenchymal samples, 50 randomly selected grid squares were evaluated and all amosite fibres identified and measured. For the airway samples, 50 grid squares were initially evaluated, but, because this examination failed to find amosite fibres in any of the airway sites, a further 250 grid squares for a total of $\mathbf{3 0 0}$ squares was examined for each sample. This number was chosen both to provide low detection limits (see below) and as a practical matter because of the extensive time involved in counting this many squares.

When it became apparent that even examination of 300 grid squares failed to show asbestos in most airway sites, a decision was made to count total mineral particles using the same grids. This count was intended as a positive control to indicate whether the preparations were faulty, or whether in fact the asbestos content of the airways was extremely low.

Results were calculated using an algorithm that relates weight of tissue dissolved and number of grid squares examined. ${ }^{6}$ All results were expressed in terms of fibres or particles/g dry tissue. The detection limit for each sample is defined as the number of fibers/g dry tissue that would be represented by the finding of 1 actual fibre in the counted grid squares (this indicates the minimum sensitivity of the technique (see discussion). Because many of the distributions shown in tables 2 and 4 are skewed, as is common with particle counts, both arithmetic and geometric mean values were calculated for presenta-

Table 2 Amosite asbestos and total particle concentration in airways

\begin{tabular}{|c|c|c|c|c|c|c|c|c|c|c|c|c|}
\hline \multirow[b]{3}{*}{ Site } & \multicolumn{12}{|l|}{ Case } \\
\hline & \multicolumn{2}{|l|}{1} & \multicolumn{2}{|l|}{2} & \multicolumn{2}{|l|}{3} & \multicolumn{2}{|l|}{4} & \multicolumn{2}{|l|}{5} & \multicolumn{2}{|l|}{6} \\
\hline & $A$ & $P$ & $A$ & $P$ & $A$ & $P$ & $A$ & $P$ & $A$ & $P$ & $A$ & $P$ \\
\hline $\begin{array}{l}\text { MAIN } \\
\text { ULB } \\
\text { APB } \\
\text { ASB } \\
\text { LLB } \\
\text { SSB } \\
\text { PBB }\end{array}$ & $\begin{array}{l}<11 \\
<13 \\
35 \\
<40 \\
<21 \\
<19 \\
<90\end{array}$ & $\begin{array}{r}54 \\
48 \\
110 \\
240 \\
86 \\
58 \\
156\end{array}$ & $\begin{array}{r}<13 \\
<29 \\
<15 \\
\quad 69 \\
<15 \\
<24 \\
36\end{array}$ & $\begin{array}{r}200 \\
28 \\
120 \\
110 \\
170 \\
260 \\
140\end{array}$ & $\begin{array}{r}<30 \\
<26 \\
<45 \\
\mathrm{ND} \\
17 \\
<81 \\
61\end{array}$ & $\begin{array}{r}100 \\
48 \\
140 \\
\text { ND } \\
98 \\
160 \\
72\end{array}$ & $\begin{array}{l}<14 \\
<60 \\
<52 \\
120 \\
<36 \\
<18 \\
<12\end{array}$ & $\begin{array}{r}18 \\
180 \\
150 \\
200 \\
32 \\
260 \\
210\end{array}$ & $\begin{array}{l}<11 \\
<33 \\
73 \\
<12 \\
<19 \\
<21 \\
<91\end{array}$ & $\begin{array}{r}140 \\
180 \\
290 \\
360 \\
56 \\
48 \\
180\end{array}$ & $\begin{array}{l}<14 \\
<28 \\
<35 \\
<45 \\
<19 \\
\text { ND } \\
<39\end{array}$ & $\begin{array}{r}140 \\
56 \\
140 \\
280 \\
26 \\
\text { ND } \\
460\end{array}$ \\
\hline
\end{tabular}

Amosite concentration in thousands of fibres/g dry tissue; Total particle concentrations in millions of particles/g dry tissue; Symbol <: less than indicated detection limit, $\mathrm{ND}=$ not analysed; $\mathrm{A}=$ amosite; $\mathrm{P}=$ particles. 
Table 3 Arithmetic mean and geometric mean for amosite asbestos and total particle concentration in airways

\begin{tabular}{lcclll}
\hline & \multicolumn{2}{l}{ Arithmetic mean } & & \multicolumn{2}{c}{ Geometric mean } \\
\cline { 2 - 3 } \cline { 5 - 6 } Site & Amosite & Particles & & Amosite & Particles \\
\hline MAIN & 0 & 110 & & 0 & 85 \\
ULB & 0 & 66 & & 0 & 54 \\
APB & 18 & 160 & & 0 & 150 \\
ASB & 38 & 240 & & 0 & 220 \\
LLB & 3 & 78 & & 0 & 65 \\
SSB & 0 & 160 & & 0 & 120 \\
PBB & 17 & 200 & 0 & 180 \\
\hline
\end{tabular}

Amosite concentration in thousands of fibres/g dry tissue; Total particle concentrations in millions of particles/g dry tissue.

tion in tables 3 and 5 . For this purpose the airways with no amosite fibres were treated as value zero. Standard deviations have been omitted from tables 3 and 5 for clarity.

\section{Results}

\section{DEMOGRAPHIC DATA}

Table 1 shows age, sex, years of exposure, latency, and time since last exposure for each case. All of the patients were non-smokers. Exposure was moderately heavy, with exposures varying from 15 years to 36 years, mean (SD) $28(8)$ years.

\section{FIBRES AND PARTICLES IN AIRWAY EPITHELIUM}

Table 2 shows these data for each case. The symbol $<$ indicates that no fibres were found, and that the possible concentration (if any) was therefore less than the indicated detection limit. In two cases one airway site was not usable so that the total number of sampled airways was 40 . Amosite fibres were detected in only seven of the 40 sample sites; no particular airway was consistently positive for asbestos fibres. When present airway amosite concentrations ranged from 35000 to 120000 fibres/g dry tissue. Nonasbestos mineral particles were present in all airways in concentrations ranging between 20 and 400 million particles/g dry tissue. Table 3 shows arithmetic and geometric mean summary data. Treating the airways with no detectable fibres as concentration
Table 5 Arithmetic mean and geometric mean for amosite asbestos and total particle concentration in parenchyma

\begin{tabular}{lcclll}
\hline & \multicolumn{2}{l}{ Arithmetic mean } & & \multicolumn{2}{c}{ Geometric mean } \\
\cline { 2 - 3 } \cline { 5 - 6 } Site & Amosite & Particles & & Amosite & Particles \\
\hline APT & 590 & 340 & & 470 & 320 \\
AST & 1000 & 310 & & 490 & 240 \\
SST & 400 & 210 & & 350 & 190 \\
PBT & 370 & 260 & 280 & 250 \\
\hline
\end{tabular}

Amosite concentration in thousands of fibres/g dry tissue; Total particle concentrations in millions of particles/g dry tissue.

values of zero, the overall arithmetic mean concentration of asbestos fibres in airways was roughly 11000 fibres/g, and the geometric mean concentration 0 fibres/g.

FIBRES AND PARTICLES IN PARENCHYMA

Tables 4 and 5 show similar data for the parenchymal sites. No parenchymal samples were prepared for the two sites with unusable airways. Amosite fibres were easily identified in every site, so that there are no entries $(<)$ indicating less than the detection limit. Concentration values ranged from 100000 to 3900000 fibres/g dry tissue. Particle counts were of the order of 100 to 800 million particles/g dry tissue.

\section{Discussion}

As noted in the introduction, there is considerable experimental evidence that pulmonary epithelial cells, including bronchial epithelial cells, take up asbestos fibres, and that this process is generally deleterious. ${ }^{1-357-11}$ Fibres that penetrate through the bronchial epithelium to the interstitium may cause release of fibrogenic mediators from interstitial macrophages and other interstitial cells. ${ }^{312}$ Fibres within epithelial cells produce various potentially mutagenic effects including DNA strand breaks and interference with the mitotic apparatus. ${ }^{13-15}$ As well, in these systems, asbestos fibres increase the transport of adsorbed carcinogens such as benzo(a)pyrene into the cells and also enhance metabolic formation of active carcinogens. ${ }^{16}$ The potential consequences of

Table 4 Amosite asbestos and total particle concentration in parenchyma

\begin{tabular}{|c|c|c|c|c|c|c|c|c|c|c|c|c|}
\hline \multirow[b]{3}{*}{ Site } & \multicolumn{12}{|c|}{ Case } \\
\hline & \multicolumn{2}{|l|}{1} & \multicolumn{2}{|l|}{2} & \multicolumn{2}{|l|}{3} & \multicolumn{2}{|l|}{4} & \multicolumn{2}{|l|}{5} & \multicolumn{2}{|l|}{6} \\
\hline & $A$ & $P$ & $A$ & $P$ & $A$ & $P$ & $A$ & $P$ & $A$ & $P$ & $A$ & $P$ \\
\hline $\begin{array}{l}\text { APT } \\
\text { AST } \\
\text { SST } \\
\text { PBT }\end{array}$ & $\begin{array}{l}210 \\
380 \\
230 \\
140\end{array}$ & $\begin{array}{l}350 \\
180 \\
300 \\
160\end{array}$ & $\begin{array}{r}160 \\
390 \\
63 \\
67\end{array}$ & $\begin{array}{l}470 \\
730 \\
100 \\
160\end{array}$ & $\begin{array}{l}480 \\
\text { ND } \\
140 \\
100\end{array}$ & $\begin{array}{l}260 \\
\text { ND } \\
130 \\
260\end{array}$ & $\begin{array}{l}540 \\
270 \\
430 \\
260\end{array}$ & $\begin{array}{l}560 \\
340 \\
330 \\
270\end{array}$ & $\begin{array}{l}340 \\
390 \\
590 \\
270\end{array}$ & $\begin{array}{l}200 \\
260 \\
190 \\
260\end{array}$ & $\begin{array}{l}360 \\
190 \\
\text { ND } \\
790\end{array}$ & $\begin{array}{r}200 \\
84 \\
\text { ND } \\
240\end{array}$ \\
\hline
\end{tabular}

Amosite concentration in thousands of fibres/g dry tissue; Total particle concentrations in millions of particles/g dry tissue; ND = not analysed; $\mathbf{A}=$ amosite; $\mathbf{P}=$ particles. 
the penetration of asbestos fibres into epithelial cells are thus clear, but despite extensive experimental work in this area, there are no data available on whether asbestos actually enters human respiratory epithelial cells in vivo.

It is known from animal model systems that inhaled mineral particles not removed by macrophages may penetrate into the respiratory epithelium and be transported through the cell to end up in the underlying interstitial tissue, from which site they are probably cleared poorly or not at all. ${ }^{17} 18$ Thus numbers of particles found in the respiratory mucosa (all tissues between the cartilage of the large airways and the epithelial surface) could potentially be used to determine patterns of particle retention in humans. In a study of airway mucosa from nonsmoking members of the general population, ${ }^{4}$ we found that the airway mucosa contained exogenous mineral particles of the order of $10^{7}$ to $10^{8} / \mathrm{g}$ dry tissue, and that the pattern of retention in terms of airway size and distance from the carina matched that predicted from theoretical models of particle deposition, ${ }^{19}$ suggesting that in fact particles retained in the airway walls are probably excellent indicators not only of retention but also of initial deposition patterns.

We have now applied this technique to examine the question as to whether asbestos fibres enter the epithelium and walls of the larger conducting airways in human lungs. The population we have used was one with fairly substantial historic exposure to asbestos, exposure sufficient to cause mesotheliomas, and sufficient to produce readily dectectable fibre concentrations in the parenchyma. We found that no fibres could be detected in $83 \%$ of the bronchial sample sites despite the presence of large numbers of nonasbestos particles in the same samples. In fact the non-asbestos particle concentrations in these airways showed the same pattern that we have previously reported ${ }^{4}$ - namely, higher concentrations in segmental compared to mainstem or upper and lower lobe bronchi (table 3 ). These findings indicate that the technique was working properly and that the aparent absence of asbestos fibres from the airways is not an analytical artifact. Even in the positive airway samples only one or at most two fibres were found in 300 grid squares, and it is entirely possible that these few fibres are contaminants from the much larger number of fibres present in the parenchyma (the actual number of fibres counted in 50 squares in the parenchymal sites varied from 14 to 50 , mean 35 ).

It should be noted that the word "absence" is not strictly correct in this context; the more accurate conclusion is that amosite fibres, if present, might be present at any level below the detection limit. But in terms of fibre burdens found in patients with occupational exposure to amosite exposure, the potential maximum burdens represented by the detection limits (average about 40000 fibres/g) or by the actual number of fibres (average about 11000 fibres $/ g$, treating the airways with no detectable fibres as value 0 ) in the airway mucosa are extraordinarily low. This fact can be best appreciated by noting that the average fibre concentration in the parenchymal samples supplied by these same airways was about 600000 fibres/g dry lung, a value typical of that we found in workers with mesothelioma ${ }^{20}$ By contrast, members of the general population usually carry no more than 10000 fibres of amosite/g of parenchyma, values fairly similar to the detection limits just mentioned.

It thus seems that the airway mucosa in humans may not accumulate many amosite asbestos fibres, but this conclusion must be made with considerable caution. For one thing, the number of cases examined is obviously small, although the fairly large number of sampled airways partly makes up for this problem. Although the persons in our study have had substantial exposure, groups of workers with considerably higher exposure do exist: in our laboratory lungs with amosite induced asbestosis typically have 10 to 100 times the fibre load found in lungs with mesothelioma, the lungs used in this study. ${ }^{20}$ The possibility that fibres do accumulate in the airway mucosa at high fibre exposures still needs to be ruled out. It is also possible that cigarette smokers accumulate more fibres in their airways than the non-smokers examined here. Smoking is believed to increase retention of particles of all types, and, at least experimentally, this applies to asbestos as well as non-asbestos particles. ${ }^{52122}$ Lastly, it is possible that fibres actually enter the bronchial mucosa but are cleared much faster from the airways than they are from the parenchyma; there are no data that allow comment about this possibility, but, with exposures of up to 36 years, it seems unlikely that all fibres would be cleared from the mucosa, particularly given the well established finding that amphibole asbestos is generally cleared very slowly from lung tissue.

There is considerable controversy on the question of whether rates of lung cancer are increased with any amount of exposure to asbestos or only in those with asbestosis. ${ }^{23-29}$ This study was not designed to consider that issue; however, the fact that we cannot show any significant amount of asbestos in the mucosa of the large airways, the airways in which bronchogenic carcinomas are believed to arise, does raise doubts about the ability of asbestos to act as a direct airway carcinogen in humans.

This work was supported by grants from the National Cancer Institute of Canada and Medical Research Council of Canada.

1 Mossman BT, Gee JBL. Asbestos-related diseases. New Engl J Med 1989;320:1721-30.

2 Mossman BT, Bignon J, Corn M, Seaton A, Gee JBL. Asbestos: Scientific developments and implications for public policy. Science 1990:294-300. 
3 Rom WN, Travis WD, Brody AR. Cellular and molecular basis of the asbestos-related disease. Amer Rev Respir Dis 1991;143:408-22.

4 Churg A, Wright JL, Stevens B. Exogenous mineral particles in the human bronchial mucosa and lung parenchyma. I. Nonsmokers in the general population. Exp Lung Res 1990;16: 169-75.

5 McFadden D, Wright J, Wiggs B, Churg A. Smoking increases the penetration of asbestos fibers into airway walls. $\mathrm{Am} \mathrm{J}$ Pathol 1986;123:95-9.

6 Churg A. Quantitative methods for analysis of disease induced by asbestos and other mineral particles using the transmission electron microscope. In: Ingram P, Shelburne JD, Roggli VL, eds. Microprobe analysis in medicine. New York: Hemisphere Publishing Co, 1989:79-96.

7 Brody AR, Hill LH. Interstitial accumulation of inhaled chrysotile asbestos fibers and consequent formation of microcalcifications. Am J Pathol 1982;109:107-14.

8 Mossman BT, Kessler JB, Ley BW, Craighead JE. Interaction of crocidolite asbestos with hamster respiratory mucosa in organ culture. Lab Invest 1977;36:131-9.

9 Hobson J, Wright JL, Churg A. Active oxygen species mediate asbestos fiber uptake by tracheal epithelial cells. FASEB $J$ 1990;4:3135-9.

10 Topping DC, Nettesheim P, Martin DH. Toxic and tumorigenic effects of asbestos on tracheal mucosa. $J$ Environ Pathol Toxicol 1980;3:261-75.

11 Haugen A, Schafer PW, Lechner JF, Stoner GD, Trump BF, Harris CC. Cellular ingestion, toxic effects, and lesions observed in human bronchial epithelial tissue and cells cultured with asbestos and glass fibers. Int J Cancer 1982; 30:265-72.

12 Adamson IYR, Letourneau HL, Bowden DH. Comparison of alveolar and interstitial macrophages in fibroblast stimulation after silica and long or short asbestos. Lab Invest 1991;64: 339-44.

13 Jackson JH, Schraufstatter IU, Hyslop PA, et al. Role of oxidants in DNA damage-hydroxyl radical mediates the synergistic DNA damaging effects of asbestos and cigarette smoke. J Clin Invest 1987;80:1090-5.

14 Cole RW, Ault JG, Hayden JH, Rieder CL. Crocidolite asbestos fibers undergo size-dependent microtubule-mediated transport after endocytosis in vertebrate lung epithelial cells. Cancer Res 1991;51:4942-7.

15 Hesterberg TW, Barrett JC. Induction by asbestos fibers of anaphase abnormalities: mechanism for aneuploidy induction and possibly carcinogenesis. Carcinogenesis 1985;6: 473-5.
16 Mossman BT, Eastman A, Landesman JM, Bresnick E. Effects of crocidolite and chrysotile asbestos on cellular uptake and metabolism of benzo(a)pyrene in hamster tracheal epithelial cells. Environ Health Perspect 1983;51:331-5.

17 Gore DJ, Patrick G. A quantitative study of the penetration of insoluble particles into the tissue of the conducting airways. Ann Occup Hyg 1982;26:149-61.

18 Bowden DH. Macrophages, dusts, and pulmonary diseases. Exp Lung Res 1987;12:89-107.

19 Gerrity TR, Lee PS, Hass FJ, Marinelli A, Wenrer P, Lourenco RV. Calculated deposition of inhaled particles in the airway generations of normal subjects. J Appl Physiol 1979;47:873-6.

20 Churg A, Wright J. Fiber content of lung in ampibole vs chrysotile induced mesothelioma: Implications for environmental exposure. In: Bignon J, Peto J, Sararri R, eds. Nonoccupational exposure to mineral fibres. Lyon: IARC, 1989: 314-18.

21 Cohen D, Arai SF, Brain JD. Smoking impairs long-term clearance from the lung. Science 1979;204:514-6.

22 Mauderly JM, Chen BT, Hahn FF, et al. The effect of chronic cigarete smoke inhalation on the long-term pulmonary clearance of inhaled particles in the rat. In: Wehner AP, ed. Biological interactions of inhaled mineral fibers and cigarette smoke. Columbus, Ohio: Battelle Press, 1989:223-40.

23 McDonald JC, McDonald AD. Epidemiology of asbestosrelated lung cancer. In: Antman K, Aisner J, eds. Asbestosrelated malignancy. New York: Grune and Stratton, 1986: 57-79.

24 Browne $\mathrm{K}$. Is asbestos or asbestosis the cause of the increased risk of lung cancer in asbestos workers? $\mathrm{Br} \mathrm{J}$ Ind Med 1986;43:145-9.

25 Hughes JR, Weill H. Asbestosis as a precursor of asbestos related lung cancer. Br J Ind Med 1991;48:229-33.

26 Sluis-Cremer GK, Bezuidenhout BN. Relation between asbestosis and bronchial cancer in amphibole asbestos miners. $\mathrm{Br} \mathrm{J}$ Ind Med 1989;46:537-40.

27 Hammond EC, Selikoff IJ, Seidman H. Asbestos exposure, cigarette smoking, and death rates. Ann NY Acad Sci 1979; 330:473-91.

28 Health Effect Institute-Asbestos Research. Asbestos in public and commercial buildings: a literature review and synthesis of current knowledge. Cambridge, MA: Health Effects Institute, 1991.

29 Davis JMG, Cowie HA. The relationship between fibrosis and cancer in experimental animals exposed to asbestos and other fibers. Environ Health Perspect 1990;88:305-9.

Accepted 6 July 1992 